\title{
THE EFFECT OF FOOD ADDITION OF SULFONIC AMINO ACID TAURINE ON THE GROWTH AND SURVIVAL RATE OF JUVENILE GOURAMY (Osphronemus gouramy Lac.)
}

\section{EFEK PENAMBAHAN SENYAWA ASAM AMINO SULFONAT TAURIN PADA PAKAN KOMERSIL TERHADAP PERTUMBUHAN DAN KELULUS HIDUPAN JUVENILE IKAN GURAMI (Osphronemus gouramy Lac.)}

\author{
Elisa N. Fitriana, Endang L.Widiastuti, Nuning Nurcahyani, M. Kanedi \\ Jurusan Biologi FMIPA, Universitas Lampung \\ E-mail : els.els0770@gmail.com \\ Jurusan Biologi FMIPA, Universitas Lampung \\ Jl. Prof.Dr. Soemantri Brojonegoro No. 1, Bandarlampung, Lampung, Indonesia, 35145
}

\begin{abstract}
Abstrak
Taurine dalam bentuk asam amino sulfonat diketahui mempengaruhi pertumbuhan dan kelangsungan hidup pada berbagai larva dan juvenil ikan perairan laut, seperti kerapu dan cobia. Namun demikian, peran taurine terhadap juvenil ikan perairan tawar, contohnya ikan gurame (Osphronemus gouramy Lac.) belum diketahui. Dengan demikian penelitian ini dilakukan untuk menentukan peran taurine terhadap pertumbuhan dan kelulushidupan juvenil ikan gurami. Penelitian dilakukan di Desa Way Linti - Kabupaten Pesawaran - Provinsi Lampung dari Bulan Desember 2013 - Februari 2014. Rancangan acak lengkap dengan 4 perlakuan digunakan dalam penelitian ini, perlakuan adalah sebagai berikut $0,1,5,2$, dan $2,5 \mathrm{~g}$ taurine $/ 1 \mathrm{~kg}$ pakan kering. Enam puluh empat juvenil dengan berat tubuh rerata $100 \mathrm{~g}$ digunakan dalam penelitian ini. Ikan diberi makan 2 kali/hari. Data dikoleksi setiap minggu dengan parameter pertambahan berat tubuh, cardiosomatic index (CSI), hepatosomatic index (HSI), visceralsomatic index (VSI), muscle ratio (MR), dan kualitas air (sebagai data penunjang). Data dianalisis menggunakan ANOVA dan Tukey's (pada $\alpha \leq 5 \%$ ). Hasil menunjukkan bahwa perlakuan III (2,5 g/1 kg pakan) meningkatkan pertumbuhan juvenil gurame yang paling baik dengan pertambahan sekitar 4-10 g/minggu. Pertambahan berat tubuh ini berkontribusi terhadap CSI, HSI, VSI, dan MR. Namun demikian, kelulushidupan antar perlakuan tidak menunjukkan perbedaan.
\end{abstract}

Kata kunci : Taurin, Gurami juvenil, Pertumbuhan, dan Kelulushidupan

\begin{abstract}
Taurine in a form of sulfonic amino acid has known to improve the growth and survival rate of marine fishes, such as groupers and cobia. Yet, its function in juvenile freshwater fishes is still unknown. Therefore, this study was conducted to determine taurine effect on juvenile Gourami's growth and survival rate. The study was carried out in Desa Way Linti - Pesawaran regency - Lampung Province from December 2013 - February 2014. Complete randomely design was assigned with four treatment groups, each groups receiving taurine in their diet as followed $0,1.5,2,2.5 \mathrm{~g} / 1 \mathrm{~kg}$ dry fish food. Sixtyfour juvenile gouramy were used in this study with average weight of 100 grams. Fishes were fed twice a day. Data was collected every week with parameters of body weight change, cardiosomatic index (CSI), hepatosomatic index (HSI), vicerosomatic index (VSI), muscle ratio (MR) and water quality (was observed for additional information). Data were analyzed using ANOVA (at $\alpha \leq 5 \%$ ) followed by Tukey pairwise comparison. The results showed that taurine $(2,5 \mathrm{~g} / 1 \mathrm{~kg})$ significantly increased juvenile gourami's body weight with body weight changes of 4-10 g/week. These body weight changes contributed to the CSI, HSI, VSI, and MR. Yet, the survival rate of all treatment groups did not show any differences.
\end{abstract}

Keywords : taurine, juvenile guramy, growth, survival rate

\section{PENDAHULUAN}

Ikan gurami (Osphronemus gouramy Lac.) merupakan ikan air tawar yang populer dan disukai oleh masyarakat Indonesia. Namun pertumbuhan ikan gurami yang lambat dan tingkat mortalitasnya yang tinggi saat juvenile dibandingkan ikan tawar-ikan tawar lainnya, 
menimbulkan kesulitan dalam pembudidayaannya. Menurut Redmont, Stapkleton, Neary, dan David (1983) di dalam tubuh, taurin mempunyai banyak fungsi terutama berperan penting dalam proses fisiologis tubuh, sta-bilitas membran, mengatur keseimbangan ion $\mathrm{Ca}$ dan $\mathrm{Na}$ pada sel, menstimulasi glikolisis dan glikogenesis, memacu pertumbuhan, osmoregulasi, dan penglihatan.

\section{BAHAN dan METODE}

Penelitian menggunakan Rancangan Acak Lengkap (RAL), dengan 3 kelompok perlakuan dan 1 kelompok kontrol (tanpa penambahan senyawa taurin). Masing-masing perlakuan menggunakan 8 kali pengulangan. Perlakuan tersebut adalah :

1. Perlakuan I : Pakan komersil $1 \mathrm{~kg}$ dengan penambahan taurin $1,5 \mathrm{~g}$

2. Perlakuan II : Pakan komersil $1 \mathrm{~kg}$ dengan penambahan taurin $2 \mathrm{~g}$.

3. Perlakuan III: Pakan komersil $1 \mathrm{~kg}$ dengan penambahan taurin $2,5 \mathrm{~g}$.

Parameter-parameter penelitian yang diamati adalah pertambahan berat, rasio pertumbuh-an spesifik (SGR), rasio konversi pakan (FCR), indeks hepato-somatik (HSI), indeks cardiosomatik (CSI), indeks visceral-somatik (VSI), rasio otot (MR), dan kelulushidupan (SR).

\section{HASIL dan PEMBAHASAN}

Tabel 1 dari hasil analisis Tukey HSD $\alpha \leq 0,05$ menunjukkan pertambahan berat tubuh ikan gurami pada empat perlakuan ini menun-jukkan perbedaan yang tidak nyata. Kelompok perlakuan III (taurin 2,5 gram) merupakan kelompok dengan pertambahan berat rerata yang paling tinggi. Perlakuan yang memiliki rerata per-tambahan berat terendah adalah kelompok ikan kontrol. Dari rerata pertam-bahan berat ini terlihat bahwa taurin mem-berikan pengaruh pada pertambahan berat. Menurut GarciaOrtega, 2009; Li et al, 2009; FEEDAP, 2012, diduga bahwa pernambahan taurin mampu meningkatkan pertumbuhan, misalnya dengan meningkatkan nafsu makan maupun dengan meningkatkan pertumbuhan organ yang membantu dalam proses per-tumbuhan seperti organ yang berperan dalam proses pencernaan, penglihatan, hingga pe-ningkatan sistem imun.

Tabel 1. Rerata pemberian pakan yang berbeda terhadap pertambahan berat tubuh ikan gurami (Osphronemus gouramy) selama 8 minggu

\begin{tabular}{ccc}
\hline Perlakuan & N & $\begin{array}{c}\text { Rerata Pertambahan } \\
\text { Berat Tubuh }(\mathrm{X} \pm \text { SEM) } \\
\text { (gram) }\end{array}$ \\
\hline (A) Taurin $0 \mathrm{~g}$ & 88 & $4.73 \pm 0,55$ \\
(B) Taurin $1,5 \mathrm{~g}$ & 62 & $6.81 \pm 0,84$ \\
(C) Taurin $2 \mathrm{~g}$ & 81 & $7.30 \pm 1,08$ \\
(D) Taurin 2,5 g & 75 & $7.83 \pm 1,08$ \\
\hline
\end{tabular}

Tabel 2. Tabel hasil perhitungan laju pertumbuhan spesifik

\begin{tabular}{ccccc}
\hline $\begin{array}{c}\text { Minggu } \\
\text { ke- }\end{array}$ & $\begin{array}{c}\text { Kontrol } \\
\text { (gram) }\end{array}$ & $\begin{array}{c}\text { Perlakuan } \\
\text { I (gram) }\end{array}$ & $\begin{array}{c}\text { Perlakuan } \\
\text { II (gram) }\end{array}$ & $\begin{array}{c}\text { Perlakuan } \\
\text { III (gram) }\end{array}$ \\
\hline 1 & 0,75 & 0,87 & 2,03 & 1,75 \\
2 & 0,80 & 0,66 & 0,88 & 0,67 \\
3 & 1,07 & 0,59 & 0,41 & 0,51 \\
4 & 0,13 & 0,24 & 0,23 & 0,06 \\
5 & 0,15 & 0,28 & 0,08 & 0,10 \\
6 & 0,28 & 0,52 & 0,28 & 0,43 \\
7 & 0,44 & - & 0,05 & 0,50 \\
8 & 0,32 & - & - & - \\
Rerata & 0,49 & 0,53 & 0,56 & 0,57 \\
\hline
\end{tabular}

Dari tabel 2 terlihat bahwa perlakuan III (taurin 2,5 gram) yang rerata laju pertumbuhan spesifik yang paling tinggi yaitu sebesar 0,57 gram dan yang terendah adalah pada kontrol. Laju spesifik yang tinggi menunjukkan bahwa ikan pada kolam perlakuan III mempunyai pertumbuhan yang paling banyak tiap harinya dibandingkan ikan pada kolam perlakuan yang lainnya.

Tabel 3. Food Convertion Ratio (Rasio Konversi Pakan / FCR) ikan gurami (Osphronemus gouramy Lac.) selama 8 minggu perlakuan

\begin{tabular}{|c|c|c|c|c|c|c|c|c|c|}
\hline \multirow{2}{*}{ Perlakuan } & \multicolumn{8}{|c|}{ Minggu ke- } & \multirow{2}{*}{$\begin{array}{c}\text { Rerata } \\
\text { (g) }\end{array}$} \\
\hline & 1 & 2 & 3 & 4 & 5 & 6 & 7 & 8 & \\
\hline Kontrol & 0,71 & 0,73 & 0,52 & 4,56 & 3,74 & 1,99 & 1,15 & 1,61 & 1,88 \\
\hline 1 & 0,64 & 0,84 & 0,89 & 2,24 & 2,00 & 1,11 & $(-)$ & $(-)$ & 1,29 \\
\hline II & 0,26 & 0,64 & 1,43 & 2,43 & 7,32 & 2,12 & 11,39 & $(-)$ & 3,66 \\
\hline III & 0,31 & 0,80 & 1,04 & 9,97 & 5,45 & 1,30 & 0,96 & $(-)$ & 2,83 \\
\hline
\end{tabular}


Tabel 3 menunjukkan rerata nilai FCR tertinggi ada pada perlakuan II dengan nilai 3,66 yang berarti bahwa ikan gurami pada perlakuan II membutuhkan 3,66 gram pakan untuk menaikkan I gram berat tubuhnya. Dan yang mempunyai nilai FCR terendah adalah ikan pada kelompok perlakuan I yaitu hanya dengan 1,29 gram pakan untuk menaikkan 1 gram berat tubuhnya. Hal ini berarti bahwa taurin pada perlakuan I yang mempunyai nilai lebih optimum dalam menaikkan berat gurami. Hal ini sesuai dengan pendapat Lunger et. al. (2007), taurin dapat meningkatkan berat tubuh dan meningkatkan efisiensi pakan, sehingga hanya sedikit pakan yang dibutuhkan untuk meningkatkan berat tubuhnya

Tabel 4. Hepato-Somatic Index (Indeks Hepato-somatik/HSI)

\begin{tabular}{ccc}
\hline Perlakuan & $\mathrm{N}$ & $\begin{array}{c}\text { Indeks Hepato-Somatik } \\
(\mathrm{X} \pm \text { SEM) gram }\end{array}$ \\
\hline (A) Taurin $0 \mathrm{~g}$ & 16 & $2,29 \pm 0,21$ \\
(B) Taurin $1,5 \mathrm{~g}$ & 12 & $2,75 \pm 0,22$ \\
(C) Taurin $2 \mathrm{~g}$ & 14 & $1,90 \pm 0,16$ \\
(D) Taurin $2,5 \mathrm{~g}$ & 14 & $1,64 \pm 0.18$ \\
\hline
\end{tabular}

Tabel 4 menunjukkan kelompok perlakuan I (taurin 1,5 gram) mempunyai rerata indeks hepato-somatik yang paling tinggi dengan nilai rerata 2,75 gram dan terendah pada kelompok perlakuan III (taurin 2,5 gram) yang mempunyai nilai rerata indeks hepato so-matiknya 1,64 gram. Dari hasil analisis lanjutan dengan menggunakan analisis Tukey HSD $\alpha \leq 0,05$ diperoleh kelompok kontrol (tanpa penambahan taurin) tidak berbeda nyata dengan kelompok perlakuan yang lainnya. Sedangkan kelompok perlakuan I (taurin 1,5 gram) berbeda nyata dengan kelompok perlakuan II dan kelompok perlakuan III. Kelompok perlakuan II (taurin 2 gram) berbeda nyata dengan kelompok perlakuan I dan tidak berbeda nyata dengan kelompok perlakuan kontrol dan kelompok perlakuan III. Kelompok perlakuan III (taurin $2,5)$ nilai indeks hepato-somatiknya berbeda nyata dengan kelompok perlakuan I namun tidak berbeda nyata dengan kelompok perlakuan II.

Tabel 5. Cardio-Somatic Index (Indeks cardiosomatik/CSI)

\begin{tabular}{ccc}
\hline Perlakuan & $\mathrm{N}$ & $\begin{array}{c}\text { Indeks Cardio-Somatik } \\
(\mathrm{X} \pm \text { SEM) gram }\end{array}$ \\
\hline (A) Taurin $0 \mathrm{~g}$ & 16 & $0,23 \pm 0,21$ \\
(B) Taurin $1,5 \mathrm{~g}$ & 12 & $0,28 \pm 0,22$ \\
(C) Taurin $2 \mathrm{~g}$ & 14 & $0,18 \pm 0,16$ \\
(D) Taurin $2,5 \mathrm{~g}$ & 14 & $0,25 \pm 0.18$ \\
\hline
\end{tabular}

Tabel 5 menunjukkan nilai indeks cardiosomatik ikan gurami pada empat perlakuan. Setelah dianalisis Tukey's HSD dengan $\alpha \leq$ 0,05 ini menunjukkan tidak adanya perbedaan yang nyata. Kelompok perlakuan I (taurin 1,5 gram) mempunyai rerata indeks cardio-somatik yang paling tinggi dengan nilai rerata 0,28 gram. Dan yang paling rendah ada pada kelompok perlakuan II (taurin 2 gram) yang mempunyai nilai rerata indeks hepato somatiknya 0,18 gram.

Tabel 6. Visceral-Somatic Index (Indeks visceral-somatik/VSI)

\begin{tabular}{ccc}
\hline Perlakuan & $\mathrm{N}$ & $\begin{array}{c}\text { Indeks Visceral-Somatik } \\
(\mathrm{X} \pm \text { SEM) gram }\end{array}$ \\
\hline (A) Taurin $0 \mathrm{~g}$ & 16 & $9,61 \pm 0,58$ \\
(B) Taurin $1,5 \mathrm{~g}$ & 12 & $11,09 \pm 0,45$ \\
(C) Taurin $2 \mathrm{~g}$ & 14 & $7,32 \pm 0,41$ \\
(D) Taurin $2,5 \mathrm{~g}$ & 14 & $7,43 \pm 0.56$ \\
\hline
\end{tabular}

Tabel 6 menunjukkan kelompok perlakuan I (taurin $1,5 \mathrm{gram}$ ) mempunyai rerata indeks visceral-somatik yang paling tinggi dengan nilai rerata 11,09 gram. Dan yang paling rendah ada pada kelompok perlakuan II (taurin 2 gram) yang mempunyai nilai rerata indeks visceral somatiknya 7,32 gram. Dari hasil analisis lanjutan dengan menggunakan analisis Tukey HSD dengan taraf signifikasi $\alpha \leq 0,05$ diperoleh hasil yang berbeda-beda. Kelompok kontrol mempunyai beda yang nyata dengan perlakuan II dan III. Sedangkan kelompok perlakuan I (taurin 1,5 gram) berbeda nyata dengan kelompok perlakuan II dan kelompok perlakuan III dan tidak berbeda nyata dengan kelompok kontrol. Kelompok perlakuan II (taurin 2 gram) berbeda nyata dengan kelompok perlakuan I dan kontrol tapi tidak berbeda nyata dengan kelompok perlakuan III. Kelompok perlakuan III (taurin 2,5 gram) nilai indeks visceralsomatiknya berbeda nyata dengan kelompok kontrol dan kelompok perlakuan I namun tidak berbeda nyata dengan kelompok perlakuan II.

Tabel 7. Muscle Ratio (Rasio Otot/MR)

\begin{tabular}{ccc}
\hline Perlakuan & $\mathrm{N}$ & $\begin{array}{c}\text { Rasio Otot }(\mathrm{X} \pm \text { SEM) } \\
\text { gram }\end{array}$ \\
\hline (A) Taurin $0 \mathrm{~g}$ & 16 & $37,27 \pm 1,17$ \\
(B) Taurin $1,5 \mathrm{~g}$ & 12 & $37,75 \pm 0,71$ \\
(C) Taurin $2 \mathrm{~g}$ & 14 & $36,12 \pm 0,68$ \\
(D) Taurin $2,5 \mathrm{~g}$ & 14 & $37,99 \pm 0.97$ \\
\hline
\end{tabular}

Tabel 7 menunjukkan kelompok perlakuan III (taurin 2,5 gram) mempunyai rerata rasio otot yang paling tinggi dengan nilai rerata $38 \mathrm{gram}$. Dan yang paling rendah ada pada kelompok perlakuan II (taurin 2,5 gram) yang mempunyai 
nilai rerata rasio otot 36,12 gram. Dari hasil analisis lanjutan dengan menggunakan analisis Tukey HSD dengan $\alpha \leq 0,05$ diperoleh seluruh kelompok kontrol dan kelompok perlakuan tidak mempunyai perbedaan yang nyata.

Tabel 8 menunjukkan nilai kelulushidupan ikan gurami selama 8 minggu penelitian yang jumlahnya dihitung setiap minggu. Dapat terlihat dari tabel diatas 3 minggu pertama perlakuan, persentase kelulushidupannya tidak mencapai $100 \%$. Minggu pertama, 2 ikan dari kolam perlakuan I hilang dan masuk kedalam kolam besar, di minggu kedua ikan di kolam perlakuan II satu ekor ikan mati. Dan pada minggu ketiga dua ekor ikan di kolam perlakuan I dan satu ekor ikan di kolam perlakuan II masuk kedalam kolam. Kelulushidupan dipengaruhi oleh faktor biotik dan abiotik. Keadaan fisik dan kimia lingkungan air merupakan faktor abiotik yang mempengaruhi tingkat kelulushidupan ikan. Ikan gurami dari penelitian ini banyak yang terserang penyakit yang disebabkan oleh mikroorganisme dan jamur. Dapat dilihat dari gambar 1 penyakit yang menyerang ikan gurami

Tabel 8. Persentase Survival Rate (Kelulushidupan/SR) per minggu

\begin{tabular}{ccccc}
\hline Minggu ke- & Kontrol & Perlakuan I & Perlakuan II & Perlakuan III \\
\hline 1 & $100 \%$ & $87,50 \%$ & $100 \%$ & $100 \%$ \\
2 & $100 \%$ & $100 \%$ & $92,86 \%$ & $92,86 \%$ \\
3 & $100 \%$ & $83,33 \%$ & $100 \%$ & $91,67 \%$ \\
4 & $100 \%$ & $100 \%$ & $100 \%$ & $100 \%$ \\
5 & $100 \%$ & $100 \%$ & $100 \%$ & $100 \%$ \\
6 & $100 \%$ & $100 \%$ & $100 \%$ & $100 \%$ \\
7 & $100 \%$ & - & $100 \%$ & $100 \%$ \\
8 & $100 \%$ & - & - & - \\
\hline Rerata & $100 \%$ & $95 \%$ & $99 \%$ & $98 \%$ \\
\hline
\end{tabular}

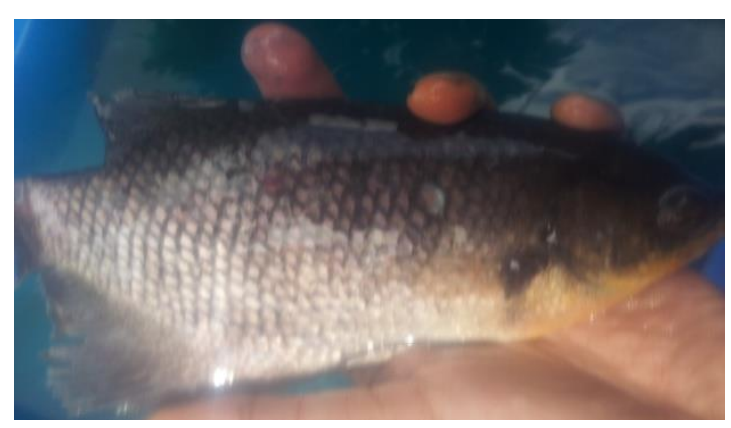

Gambar 1. Ikan gurami yang terserang penyakit

Penyakit yang menyerang ini diduga merupakan vibriosis. Pendarahan diawali dengan kemerahan dan lapisan darah yang ada terbentuk dibawah kulit (sisik) ikan dan akan menjadi titik-titik merah yang terbentuk di area ventral dan lateral ikan. Luka gelap yang membengkak akan terbentuk, yang kemudian akan berubah menjadi borok dan mengeluarkan nanah bercampur darah. Dapat juga menyebabkan mata yang keruh, yang dapat berakibat matanya keluar dan matanya hilang (animal-world.com, 2012).

Ikan yang terkena penyakit ini kebanyakan ikan dari kolam kontrol, perlakuan II, dan pada perlakuan III, kolam I juga terserang penyakit vibriosis ini tapi tidak ada yang ikan yang mati dan tidak separah dibandingkan ikan yang terkena vibriosis ini di kolam perlakuan yang lainnya, namun walaupun banyak terserang penyakit vibriosis ini, ikan pada kolam perlakuan III dengan dosis taurin yang paling tinggi, pada akhir penelitian penyakit vibriosisnya sudah sembuh. Padahal semua kolam diberikan pengobatan yang sama yaitu dengan diberikan methylen blue saat pengambilan data tiap minggunya.

Selain dipengaruhi oleh nutrisi yang diperoleh dari makanannya, pertumbuhan ikan gurami juga sangat dipengaruhi oleh kualitas lingkungan air yang baik agar pertumbuhannya optimal. parameter yang digunakan untuk pengukuran kualitas air adalah suhu, $\mathrm{pH}, \mathrm{DO}$ (dissolve oxygen/oksigen terlarut), dan kandungan nitrat. Parameter-parameter ini diambil setiap minggunya. Pengukuran kualitas air ini kemudian dapat digunakan untuk melihat bagaimana keadaan lingkungan air saat gurami tumbuh optimal ataupun saat ikan gurami tersebut tidak tumbuh dengan optimal. hasil pengukuran kualitas air dapat dilihat pada tabel 9.

Dari hasil pengukuran kualitas air selama penelitian, data yang diperoleh masih kurang baik dengan oksigen terlarut hanya 1,5-2 ppm. Untuk pertumbuhan ikan gurami yang optimum menurut pernyataan Djarijah dan Puspowardoyo (1992), suhu yang ideal untuk pertumbuhan gurami antara $24-29^{\circ} \mathrm{C}$, derajat 
keasaman $(\mathrm{pH})$ 6,5-8, dan kandungan oksigen terlarutnya 3-5 ppm.

Menurut Wardoyo (1981), salah satu faktor penentu dalam pertumbuhan suatu budidaya ikan yaitu lingkungan yang stabil seperti kualitas fisika-kimia air yang baik di setiap tempat pemeliharaan.

Tabel 9. Data pengukuran kualitas air

\begin{tabular}{cccccccccc}
\hline Parameter & \multicolumn{7}{c}{ Minggu ke } & $\begin{array}{c}\text { Standar kualitas air } \\
\text { gurami }\end{array}$ \\
\cline { 2 - 8 } & $\mathrm{I}$ & $\mathrm{II}$ & $\mathrm{III}$ & $\mathrm{IV}$ & $\mathrm{V}$ & $\mathrm{VI}$ & $\mathrm{VII}$ & $\mathrm{VIII}$ & $24-29\left({ }^{\circ} \mathrm{C}\right)$ \\
\hline Suhu $\left({ }^{\circ} \mathrm{C}\right)$ & 26 & 27 & 26 & 26 & 27 & 26 & 27 & 26 & $6-8$ \\
$\mathrm{pH}$ & 7 & 7 & 7 & 7 & 7 & 7 & 7 & 7 & $3-5 \mathrm{mg} / \mathrm{L}$ \\
DO & 1,3 & 1,5 & 1,6 & 1,7 & 1,8 & 1,9 & 1,9 & 1,9 & Rendah $(\mathrm{r})$ \\
Nitrat & $\mathrm{r}$ & $\mathrm{r}$ & $\mathrm{r}$ & $\mathrm{r}$ & $\mathrm{r}$ & $\mathrm{r}$ & $\mathrm{r}$ & $\mathrm{r}$ & \\
\hline
\end{tabular}

\section{KESIMPULAN}

1. Hasil penelitian yang memberikan efek pertumbuhan yang paling baik adalah perlakuan III dengan penambahan dosis taurin 2,5 gram.

2. Berdasarkan persentase kelulushidupan ikan gurami dari hasil penelitian, penambahan taurin tidak terlalu mempengaruhi tingkat kelulushidupan.

3. Namun berdasarkan pengamatan, taurin memberikan pengaruh pada kesehatan dan kelulushidupan juvenil ikan gurami.

\section{UCAPAN TERIMA KASIH}

Terima kasih disampaikan kepada Proyek Hibah Bersaing BOPTN T.A. 012/014 DIKTI untuk dana yang diberikan kepada kami sehingga penelitian ini dapat terlaksana.

\section{DAFTAR PUSTAKA}

Animal-world.com. 2012. Aquarium Fish Disease and Treatments. http://animalworld.com/encyclo/fresh/infinformat/Dise ases.htm\#VibVibrio. Diakses pada tanggal 20 Maret 2014 pukul 19.00 .
Djarijah, A.S \& H. Puspowardoyo. (1992). Membudidayakan Gurami secara Intensif. Yogyakarta. Kanisius.

EFSA Panel on Additive and Products or Substances used in Animal Feed (FEEDAP). 2012.Scientific Opinion on the safety and efficacy of taurine as a feed additive for all animal species. EFSA Journal: 10(6):2736. [17 pp.] doi:10.2903/j.efsa.2012.2736.

Garcia-Ortega, A. 2009. Nutrition and feeding research in the spotted rose snapper (Lutjanus guttatus) and bullseye puffer (Sphoeroides annulatus), new species for marine aquaculture. Fish Physiol Biochem. $\quad 35 \quad$ (1):69-80. Doi: 10.1007/s10695-0089226-1.

Li P, Mai K, Trushenski J, Wu G. 2009. New development in fish amino acid nutrition: towards functional and enviromentally oriented aquafeeds. Amino Acids 37(1):43-53. doi: 10.1007/s00726-0080171.

Redmont H., P. Stapkleton, Neary, dan David. 1983. Immunistrition. The ple of Taurine Nutrition 14. 559-604.

Wardoyo. S. T. 1981. Kriteria Kualitas Air Untuk Perikanan Dalam Analisa Dampak Lingkungan. PLN-PUDSI. IPB. Bogor. 